DOI: $10.29303 /$ jrpb.v9i1.214

ISSN 2301-8119, e-ISSN 2443-1354

Tersedia online di http://jrpb.unram.ac.id/

\title{
DESAIN DAN UJI KINERJA ALAT TANAM BIJI JAGUNG SISTEM DORONG BARIS GANDA DI LAHAN TANPA OLAH TANAH
}

\author{
Design and Performance Test of Corn Seeds Planter \\ of Double Row Push System on Land without Tillage \\ Ansar*), Murad, Sukmawaty, Fakhrul Irfan Khalil, Ahyar Ulumuddin \\ Program Studi Teknik Pertanian, Fakultas Teknologi Pangan dan Agroindustri, Universitas \\ Mataram, J1. Majapahit No. 62, Mataram 83125, Indonesia \\ E-mail*): ansar72@unram.ac.id \\ Diterima: November 2020 \\ Disetujui: Maret 2021
}

\begin{abstract}
Planting corn kernels is still done using a drilling system. This kind of planting tool is not optimal because it takes a long time, and the spacing is irregular. Thus, this study aimed to design and conduct a performance test of a double row push system for increasing the efficiency and productivity of land without tillage. The research begins with identifying land conditions, then determining design parameters, drawing tool designs, assembling and testing the planting tools' performance. The results showed that the actual field capacity (AFC) was 0.27 ha/hour, the theoretical field capacity (TFC) was 0.31 ha/hour, and the tool efficiency (TE) was $85.11 \%$. The distance between the rows of plants was $20.87 \mathrm{~cm}$ and the width of the rows was $35.06 \mathrm{~cm}$. Based on field tests, it was known that this tool can be used properly and can accelerate the planting of corn kernels on land without tillage.
\end{abstract}

Keywords: seeds planter; corn seed; field capacity; without tillage

\begin{abstract}
ABSTRAK
Penanaman biji jagung masih dilakukan dengan menggunakan alat tugal. Penggunaan alat tanam seperti ini kurang optimal karena membutuhkan waktu lama dan jarak tanam tidak beraturan. Dengan demikian, tujuan penelitian ini adalah mendesain dan menguji alat tanam biji jagung sistem dorong baris ganda untuk meningkatkan efisiensi dan produktivitas lahan tanpa olah tanah. Penelitian diawali dengan mengidentifikasi kondisi lahan, kemudian menetapkan parameter desain, membuat gambar desain alat, melakukan perakitan, dan uji kinerja alat tanam. Hasil penelitian menunjukkan bahwa kapasitas lapangan aktual (KLA) adalah 0,27 ha/jam, kapasitas lapangan teoritis (KLT) adalah 0,31 ha/jam, dan efisiensi alat (EA) adalah 85,11\%. Jarak antar baris tanaman adalah 20,87 $\mathrm{cm}$ dan lebar baris tanaman adalah $35,06 \mathrm{~cm}$. Berdasarkan uji lapangan diketahui bahwa alat ini dapat digunakan dengan baik dan bisa mempercepat proses penanaman biji jagung di lahan tanpa olah tanah.
\end{abstract}

Kata kunci: alat tanam; biji jagung; kapasitas lapang; tanpa olah tanah 


\section{PENDAHULUAN}

Jagung (Zea mays L.) merupakan jenis tanaman terbanyak kedua setelah padi yang banyak dibudidayakan di Indonesia (Syafruddin, et al., 2012). Pada awalnya tanaman ini berasal dari daerah tropis, namun saat ini telah berkembang dengan pesat dan tidak menuntut persyaratan khusus untuk bisa tumbuh dengan baik (Permanasari \& Kastono, 2012).

Saat ini kebutuhan jagung terus meningkat seiring dengan ragam pemanfaatan jagung, baik untuk pemenuhan kebutuhan manusia, maupun untuk pengolahan pakan ternak (Karima, et al., 2013). Namun, produksi jagung belum mampu untuk memenuhi permintaan tersebut (Nariratih, et al., 2013). Luas budidaya jagung juga menunjukkan peningkatan signifikan dari 0,7 ha menjadi 1,5 ha (Ansar, et al., 2020). Guna mendukung peningkatan produktivitas jagung, diperlukan dukungan penerapan alat dan mesin budidaya jagung yang tepat dan bersifat spesifik lokasi (Syafa'at \& Subantoro, 2017).

Menanam biji jagung pada umumnya dilakukan dengan memasukkan biji ke dalam lubang dengan kedalaman 3-7 cm menggunakan alat tugal (Pomalingo, 2020). Masing-masing lubang diisi dengan biji yang jumlahnya tidak tetap, tergantung jumlah yang terambil di tangan pekerja (Djoyowasito, et al., 2017). Jarak tanam terkadang tidak teratur, sehingga pada saat bibit tumbuh, jarak antar tanaman ada yang terlalu berdekatan dan ada pula yang berjauhan (Wirawan, et al., 2018).

Selama ini metode menanam biji jagung yang dilakukan oleh petani masih menggunakan alat tugal, akibatnya kedalaman dan jarak tanaman tidak seragam dan tidak teratur, sehingga kurang optimal (Ansar, et al., 2020). Pemakaian alat tugal sangat tidak efisien dari segi biaya, tenaga, dan waktu yang dibutuhkan (Pomalingo, 2020). Selain itu, membutuhkan waktu yang terlalu lama dan sangat melelahkan karena para pekerja harus bekerja dalam posisi jongkok untuk memasukkan biji jagung ke dalam tanah dan menutupi lubang dengan tanah kembali (Iskandar, et al., 2017). Jika pekerjaan ini dilakukan secara terusmenerus dalam jangka waktu yang cukup lama, maka bisa dipastikan sangat mengganggu kesehatan pekerja karena tulang punggung akan terasa pegal dan sakit (Ansar, 2011).

Saat ini sudah banyak hasil penelitian tentang alat tanam semi mekanis yang dirancang untuk mempermudah petani dalam melakukan pekerjaan budidaya jagung (Idhansyah, et al., 2019). Akan tetapi, alat tanam semi mekanis yang telah dirancang pada umumnya belum optimal untuk menghasilkan jumlah populasi tanaman karena jarak tanam yang belum teratur dengan baik. Jarak tanam yang optimal adalah $20 \quad$ x $35 \mathrm{~cm}$ untuk menghasilkan populasi tanaman sekitar 98 ribu/ha (Jaya, et al., 2015).

Jumlah populasi tanaman yang tinggi masih memungkinkan tanaman jagung untuk dapat memaksimalkan intersepsi cahaya matahari untuk proses fotosintesis yang dapat meningkatkan produktivitas lahan (Andrade, et al., 2002). Dengan demikian, perlu dikembangkan alat tanam biji jagung yang dapat mengatur jarak tanam dengan presisi yang tinggi agar produktivitas lahan dapat meningkat secara optimal. Oleh karena itu, penelitian ini bertujuan untuk mendesain dan menguji kinerja alat tanam biji jagung sistem dorong baris ganda untuk meningkatkan efisiensi waktu dan tenaga petani jagung.

\section{METODE PENELITIAN}

\section{Bahan dan Alat Penelitian}

Bahan utama yang digunakan untuk pembuatan alat tanam biji jagung sistem dorong baris ganda, antara lain besi cor, besi silinder, besi siku, besi pelat, aluminium, plastik akrilit, pegas, laker, rantai besi. Bahan penunjang yang dibutuhkan adalah kawat las, dempul, meni, cat, dan amplas. Peralatan utama yang digunakan adalah mesin potong listrik, las listrik, mesin bor, 
dan mesin gergaji besi, sedangkan peralatan penunjang adalah kunci pas, ring, dan sock. Bahan uji yang digunakan adalah benih jagung varietas Bisi yang dibeli di pasar lokal di Mataram, NTB. Sedangkan alat ukur penelitian yang digunakan adalah tachometer digital, timbangan digital, stopwatch, pita ukur, dan rollmeter.

\section{Prosedur Desain dan Perakitan Alat}

Proses desain dan perakitan alat dilaksanakan di Laboratorium Daya dan Mesin Pertanian Program Studi Teknik Pertanian Universitas Mataram. Proses diawali dengan identifikasi kondisi lahan tanaman jagung, penetapan parameter desain, pembuatan gambar sketsa alat tanam, pembuatan desain alat menggunakan software Autocad, pengadaan bahan dan komponen alat, dan terakhir perakitan alat tanam.

Analisis rancangan pada setiap komponen alat tanam biji jagung sistem dorong baris ganda dilakukan untuk mengetahui kesesuaian antar komponen. Komponen-komponen utama yang dianalisis adalah tangkai kemudi, mulut tanam, tangki biji, rotor penjatah benih, jumlah biji yang jatuh per lubang, putaran roda, kedalaman penanaman di permukaan tanah, dan penutup lubang.

Spesifikasi alat tanam biji jagung sistem dorong baris ganda yang telah dirancang memiliki 5 (lima) bagian utama (Gambar 1), yaitu:

1. Tangkai kemudi berfungsi untuk mendorong, mengarahkan, menjaga keseimbangan, dan mengendalikan alat.

2. Mulut tanam berfungsi untuk membuka alur tanah agar biji dapat jatuh ke dalam lubang tanah.

3. Rotor penjatah biji berfungsi untuk mengatur penjatuhan biji dalam jumlah tertentu.

4. Tangki biji berfungsi untuk menampung biji sebelum ditanam yang bisa mengalir jatuh berdasarkan gaya gravitasi bumi menuju pengatur penjatah biji.
5. Penutup lubang berupa roda berbentuk tabung silinder yang berfungsi menutup lubang setelah ditaburi biji.

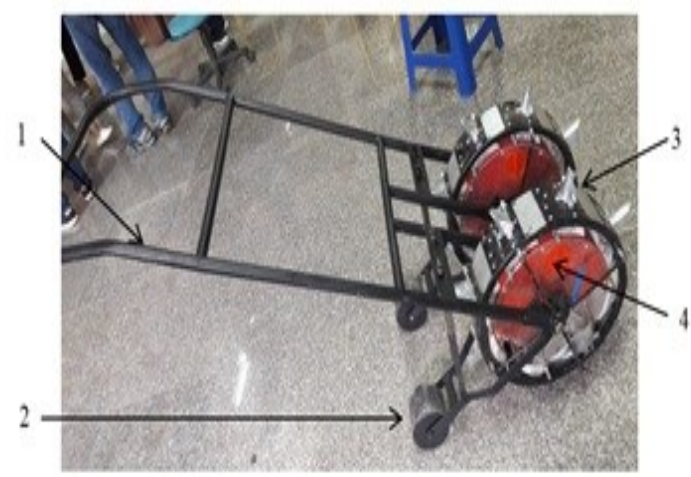

Gambar 1. Alat tanam biji jagung sistem dorong baris ganda: (1) tangkai kemudi, (2) roda penutup lubang, (3) alat penjatah benih,

(4) tempat pemasukan benih

Tangkai kemudi alat tanam terbuat dari besi silinder berdiameter 2,5 $\mathrm{mm}$. Mulut tanam berbentuk tirus dengan ukuran 80 mm. Rotor penjatah dan tangki bernih terbuat dari plastik akrilik setebal $0,3 \mathrm{~mm}$. Alat penutup lubang terbuat besi silinder dengan diameter $100 \mathrm{~mm}$.

\section{Uji Kapasitas Alat}

Uji kapasitas alat tanam biji jagung sistem dorong baris ganda dilakukan di laboratorium dan di lahan sawah tanpa olah tanah. Uji laboratorium dilakukan untuk memastikan seluruh komponen alat dapat bekerja sesuai dengan fungsinya, antara lain sistem transmisi, kecepatan putaran roda, mekanisme sistem penjatah biji, jumlah biji per lubang, dan mekanisme kerja penutup lubang. Selanjutnya, dilakukan uji lapangan di lahan sawah berukuran panjang $25 \mathrm{~m}$ dan lebar $15 \mathrm{~m}$ (Gambar 2).

Jarak antara dan lebar baris tanaman biji jagung yang ditetapkan pada alat adalah $20 \times 35 \mathrm{~cm}$. Pada saat alat tanam melintas di lahan sawah dilakukan pengukuran kecepatan maju (Vm) dengan waktu tempuh untuh jarak $10 \mathrm{~m}$ (t10). Berdasarkan data ini, dapat dihitung kapasitas lapangan aktual (KLA), kapasitas lapangan teoritis (KLT), dan efisiensi lapangan (EL) menggunakan 
Persamaan 1, 2, dan 3 berturut-turut (Hermawan, 2011).

$$
\begin{aligned}
& K L A=\frac{L_{l}}{W_{t}} \\
& K L T=0,36(V . j t) \\
& E_{A}=\frac{K L A}{K L T} \times 100
\end{aligned}
$$

\section{Dengan:}

KLA = kapasitas lapangan aktual (ha/jam)

$\mathrm{KLT}=$ kapasitas lapangan teoritis (ha/jam)

$\mathrm{Ll}=$ luas lahan tertanam (ha)

$\mathrm{Wt}=$ waktu total yang digunakan untuk menanam (jam)

$\mathrm{V}=$ kecepatan maju alat di lahan ( $\mathrm{m} /$ detik)

$\mathrm{jt}=$ jarak antar tanaman $(\mathrm{m})$

$0,36=$ faktor konversi $\left(\mathrm{m}^{2} /\right.$ detik $\left.=0,36 \mathrm{ha} / \mathrm{jam}\right)$

$\mathrm{E}_{\mathrm{A}}=$ efisiensi alat (\%)

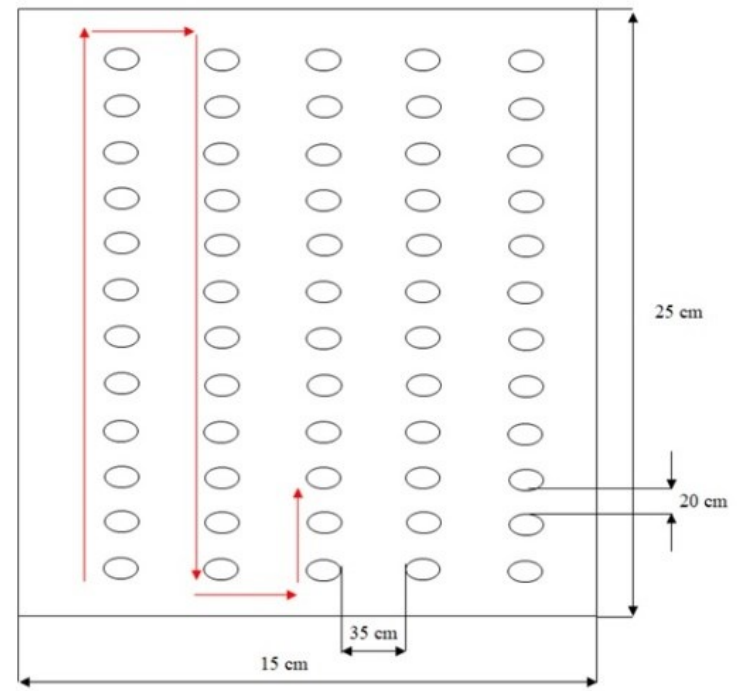

Gambar 2. Sketsa pengambilan data di lapangan

\section{Analisis Data}

Anaisis data yang digunakan adalah analisis regresi untuk mengevaluasi hubungan antara parameter desain terhadap KLA, KLT, dan EA alat tanam biji jagung sistem dorong baris ganda. Keeratan hubungan ditandai dengan nilai koefisien diterminasi $\left(\mathrm{R}^{2}\right)$. Semakin tinggi nilai $\mathrm{R}^{2}$ berarti terdapat hubungan yang erat (Ansar, et al., 2012).

\section{HASIL DAN PEMBAHASAN}

\section{Uji Kinerja Alat}

Uji kinerja alat tanam biji jagung sistem dorong baris ganda dilakukan pada 2 (dua) lokasi yang berbeda, yaitu di laboratorium dan di lahan sawah tanpa olah tanah. Uji di laboratorium bertujuan untuk memastikan setiap komponen alat dapat bekerja maksimal sesuai dengan fungsinya. Beberapa komponen penting yang telah diuji, antara lain sistem transmisi, kecepatan putaran roda, mekanisme sistem penjatah biji, jumlah biji per lubang, dan mekanisme kerja penutup lubang.

Langkah awal pengujian yang dilakukan di laboratorium adalah melakukan pengoperasian alat tanam biji jagung baris ganda ini dengan cara mendorong tangkai kemudi sambil memperhatikan kecepatan putaran roda, tuas pengungkit penjatah biji, dan proses jatuhan biji di ujung mulut tanam (Gambar 3). Hasil pengujian awal ini menunjukkan bahwa setelah roda berputar, terjadi sistem transmisi yang menghubungkan antara tuas pengungkit yang menyatu dengan mulut tanam untuk membuka alur tanah agar biji dapat jatuh ke dalam lubang tanah, kemudian diikuti oleh penutup lubang.

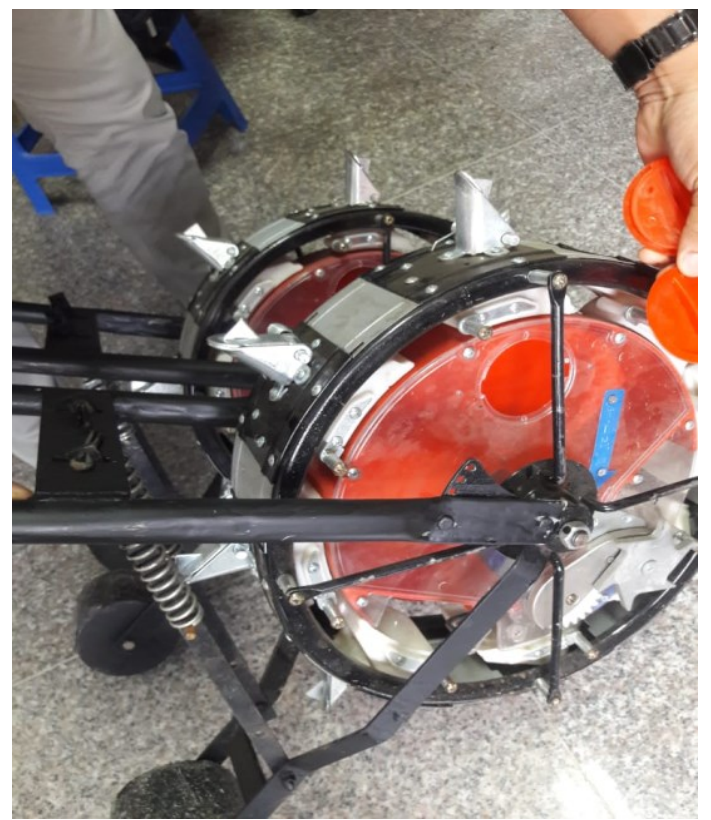

Gambar 3. Uji kinerja alat tanam biji jagung sistem dorong baris ganda di laboratorium 
Setelah dilakukan uji laboratorium, diperoleh hasil yang menunjukkan bahwa semua komponen alat tanam biji jagung baris ganda sistem dorong telah berfungsi dengan baik. Lalu dilanjutkan uji lapangan di lahan sawah milik petani di Desa Gumantar Kabupaten Lombok Utara (Gambar 4). Luas lahan yang digunakan untuk uji lapangan adalah $375 \mathrm{~m}^{2}(25 \times 15$ $\mathrm{m})$. Jarak dan baris tanaman telah ditentukan berdasarkan hasil penelitian pendahuluan yaitu $0,2 \times 0,35 \mathrm{~m}$.

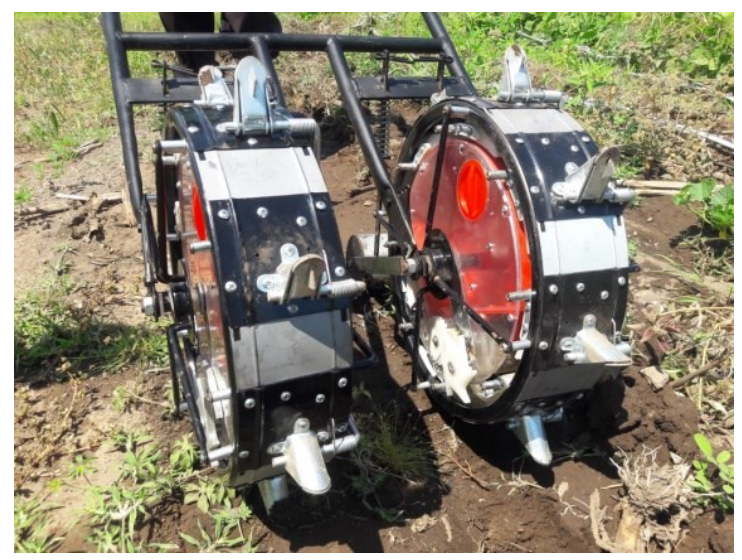

Gambar 4. Uji lapangan alat tanam biji jagung sistem dorong baris ganda di lahan sawah milik petani di Desa Gumantar Kabupaten Lombok Utara

Untuk mendapatkan hasil pengujian yang maksimal dan presisi, uji lapangan dilakukan di lahan sawah milik petani agar kinerja alat dapat dilihat secara langsung oleh calon pengguna, yaitu petani jagung. Lokasi uji lapangan ini merupakan lahan sawah tadah hujan yang kondisinya kering pada saat dilakukan pengujian tanpa olah tanah. Proses pengujian dimulai dari pemasukan biji jagung di tangki penampungan biji sampai pada pengamatan jumlah biji yang keluar dan tertanam di dalam lubang.

Hasil pengujian di lapangan menunjukkan bahwa kinerja alat tanam biji jagung sistem dorong baris ganda ini masih belum sempurna. Hal ini terlihat pada saat alat tanam melintasi tekstur tanah yang keras dan berbatu, mulut tanam tidak bisa membuka alur tanah yang sesuai untuk kebutuhan kedalaman lubang. Hal ini terjadi karena bobot alat yang masih ringan karena tangki biji belum diisi penuh sesuai kapasitas maksimal. Selain itu, kondisi lahan sawah tanpa olah tanah yang sangat keras menyebabkan sulit terbentuk alur. Hal yang sama pernah dilaporkan oleh peneliti sebelumnya (Sianipar \& Fatoni, 2019) bahwa kondisi struktur tanah yang keras sangat sulit terbentuk alur tanam pada saat ditugal, sehingga jarak tanaman terkadang tidak teratur sesuai jarak yang diinginkan. Lebih lanjut Idhansyah, et al. (2019), mengatakan bahwa hasil jarak tanam yang diperoleh pada setiap petakan dapat berbeda-beda karena disebabkan tidak ratanya permukaan tanah, sehingga pada saat alat tanam melintas di lintasan tanam terdapat bedeng yang membuat alat tersebut bergeser.

\section{Kinerja Penanaman}

Hasil pengukuran pada petak 1 diperoleh jarak antara baris tanaman ratarata $21,36 \mathrm{~cm}$ dan lebar baris tanaman ratarata $34,75 \mathrm{~cm}$. Untuk petak 2 diperoleh jarak antara baris tanaman rata-rata $20,12 \mathrm{~cm}$ dan lebar baris tanaman rata-rata $35,27 \mathrm{~cm}$. Sedangkan pada petak 3 ditemukan jarak antara baris tanaman rata-rata $21,13 \mathrm{~cm}$ dan lebar baris tanaman rata-rata $35,16 \mathrm{~cm}$ (Tabel 1).

Tabel 1. Jarak tanaman setiap petak

\begin{tabular}{ccc} 
Petak & $\begin{array}{c}\text { Jarak antar baris } \\
\text { tanaman }(\mathrm{cm})\end{array}$ & $\begin{array}{c}\text { Lebar baris } \\
\text { tanaman }(\mathrm{cm})\end{array}$ \\
\hline I & 21,36 & 34,75 \\
II & 20,12 & 35,27 \\
III & 21,13 & 35,16 \\
\hline Rata-rata & 20,87 & 35,06 \\
\hline
\end{tabular}

Data pada Tabel 1 menunjukkan bahwa jarak dan lebar baris tanaman yang diperoleh dari setiap petak memiliki nilai rata-rata yang berbeda-beda. Hal ini diduga terjadi karena kountur dan struktur tanah yang tidak rata, sehingga pada saat alat tanam melintas terdapat tumpukan yang dapat menyebabkan alat tanam bergeser. 
Faktor lain yang berpengaruh terhadap perbedaan nilai rata-rata adalah teknis pengukuran, namun nilai standar deviasi yang sangat kecil, yaitu $0,63 \mathrm{~cm}$. Hal yang sama pernah dilaporkan oleh Marliah, et al. (2010), bahwa perbedaan antara jarak dan baris tanaman disebabkan oleh adanya perbedaan permukaan tanah pada setiap petakan lahan.

Hasil penelitian Neo \& Ceunfin (2018) juga melaporkan bahwa jarak tanaman berpengaruh secara signifikan terhadap hasil panen jagung. Jarak tanaman $60 \times 25 \mathrm{~cm}$ memberikan hasil yang lebih besar jika dibandingkan dengan jarak tanaman $75 \times 25 \mathrm{~cm}$ dan $90 \times 25 \mathrm{~cm}$. Jarak tanaman yang terlalu berjauhan dapat menurunkan hasil panen sebesar $15 \%$ pada jarak tanaman $75 \times 25 \mathrm{~cm}$ dan $29 \%$ pada jarak tanaman $90 \times 25 \mathrm{~cm}$. Oleh karena itu, untuk meningkatkan hasil panen tanaman jagung menurut peneliti sebelumnya (Silaban, et al., 2013) adalah melakukan pengaturan jarak dan baris tanaman per satuan luas. Jarak tanaman jagung sangat berhubungan erat dengan ruang tumbuh. Jarak tanaman yang terlalu renggang tidak efisien dalam pemanfatan lahan, sebaliknya apabila terlalu rapat terjadi persaingan untuk mendapatkan unsur hara, air, dan cahaya matahari yang mengakibatkan produktifitas berkurang.

Banyak faktor yang dapat mempengaruhi pertumbuhan tanaman jagung, salah satunya adalah jarak tanaman. Menurut Yulisma (2015), peningkatan pertumbuhan tanaman jagung dapat dilakukan dengan metode pengaturan jarak dan baris tanaman agar mencapai pertumbuhan yang maksimal. Lebih lanjut Bolly (2018), menjelaskan bahwa pengaturan jarak tanaman dapat meminimalkan kompetisi intra dan inter spesies populasi dan jumlah tanaman yang berlebihan dapat mengurangi terjadinya persaingan faktor-faktor pertumbuhan tanaman, seperti unsur hara, air, radiasi matahari, dan ruang pertumbuhan.

Sebaliknya, menurut Aisyah \& Herlina (2018), jarak tanaman yang terlalu lebar, walaupun mampu memperbaiki pertumbuhan kanopi dan akar tanaman secara individual, tetapi memberikan peluang tumbuhnya gulma. Tanaman jagung yang disertai pertumbuhan gulma dapat merugikan karena terjadi kompetisi dalam pemanfaatan unsur hara, air, cahaya, dan ruang tumbuh (Khodijah, et al., 2014). Jarak tanaman yang renggang, selain mengurangi jumlah populasi tanaman, juga mengurangi pemanfaatan cahaya matahari dan unsur hara tanaman, karena sebagian radiasi matahari hanya jatuh ke permukaan tanah dan unsur hara dapat hilang sebagai akibat dari penguapan (Wiresyamsi, et al., 2018). Yulisma (2015) juga melaporkan bahwa jarak tanaman yang terlalu berdekatan dapat mengganggu pertumbuhan, tetapi jika terlalu berjauhan dapat mengurangi jumlah tanaman per satuan luas.

Hasil yang diperoleh dari penelitian ini mendukung hasil penelitian Wiresyamsi, et al. (2018), yang menunjukkan bahwa pengaturan jarak tanaman sangat penting dilakukan untuk menghasilkan pertumbuhan tanaman yang sama, pendistribusian unsur hara yang seragam, efisiensi penggunaan lahan, dapat mempermudah perawatan, mampu menekan pertumbuhan hama dan penyakit, dan juga dapat mengetahui jumlah benih yang dibutuhkan untuk penanaman. Selain itu, menurut Farida, et al. (2017), penggunaan jarak tanam yang terlalu berdekatan dapat menyebabkan daun kanopi jagung saling terganggu, sehingga pertumbuhan tanaman menjulang tinggi ke atas dan memanjang karena adanya persaingan untuk memperoleh sinar matahari. Akibat jangka panjang adalah mengganggu proses fotosintesis dan produktivitas tanaman tidak bisa optimal. Pada prinsipnya pengaturan jarak tanaman bertujuan untuk memberikan kesempatan kepada tanaman agar dapat tumbuh dengan baik tanpa mengalami gangguan dengan memanfaatkan lingkungan secara maksimal.

\section{Efisiensi Alat}

Berdasarkan hasil pengujian di lapangan diperoleh nilai kapasitas lapangan 
aktual (KLA), kapasitas lapangan teoritis (KLT), dan efisiensi alat (EA) seperti ditunjukkan pada Tabel 2. Pada tabel tersebut terlihat bahwa nilai KLA rata-rata sebesar $0,27 \mathrm{ha} / \mathrm{jam}$, sedangkan untuk nilai KLT rata-rata sebesar $0,31 \mathrm{ha} / \mathrm{jam}$, sehingga efisiensi alat tanam diperoleh rata-rata sebesar 85,11\%. Pada petak 1 diperoleh efisiensi alat tanam paling tinggi jika dibandingkan dengan petak 2 dan 3 . Hal ini diduga karena kondisi awal alat tanam dalam keadaan siap untuk dioperasikan. Pada petak 2 dihasilkan efisiensi alat tanam paling rendah jika dibandingkan dengan petak 1 dan 3. Efisiensi alat tanam yang rendah di petak 2 disebabkan karena ada waktu yang digunakan untuk belok, sehingga berpengaruh terhadap kapasitas lapangan aktual (KLA).

Tabel 2. Data efisiensi alat tanam biji jagung sistem dorong baris ganda

\begin{tabular}{cccc}
\hline Petak & $\begin{array}{c}\text { KLA } \\
\text { (ha/jam) }\end{array}$ & $\begin{array}{c}\text { KLT } \\
\text { (ha/jam })\end{array}$ & EA (\%) \\
\hline I & 0,27 & 0,31 & 87,10 \\
II & 0,26 & 0,31 & 83,87 \\
III & 0,27 & 0,32 & 84,38 \\
\hline Rata-rata & 0,27 & 0,31 & 85,11 \\
\hline
\end{tabular}

Hasil yang diperoleh dari perhitungan efisiensi alat adalah $85,11 \%$ untuk luasan lahan 0,0375 ha $(25 \times 15 \mathrm{~m})$. Efisiensi alat tergantung dari perbandingan nilai KLA dan KLT (Tabel 2). Efisiensi yang diperoleh dari penelitian ini lebih tinggi $3,11 \%$ dari pada hasil penelitian yang dilakukan oleh Djoyowasito, et al. (2017), tentang uji performansi dan rancang bangun mesin penanam benih jagung sistem tugal yang hanya menghasilkan efisiensi $82 \%$.

Nilai efisiensi alat tanam biji jagung sistem dorong baris ganda sangat dipengaruhi oleh lamanya waktu yang digunakan pada saat menanam biji jagung. Selain itu, efisiensi juga dipengaruhi oleh kondisi tanah lahan yang keras dan kurang gembur karena tidak dilakukan pengolahan tanah. Adanya alang-alang dan tumbuhan lain juga berpengaruh terhadap efisiensi. Semakin cepat waktu penanaman, semakin efisien penggunaan waktu dan tenaga kerja. Hal yang serupa pernah dilaporkan oleh Idhansyah, et al. (2019), bahwa waktu penanaman yang relatif singkat dapat memberikan efisiensi yang lebih tinggi pula.

\section{KESIMPULAN DAN SARAN}

\section{Kesimpulan}

Berdasarkan hasil uji lapangan alat tanam biji jagung sistem dorong baris ganda pada lahan seluas $735 \mathrm{~m}^{2}$, dapat disimpulkan bahwa alat dapat berfungsi dengan baik untuk menanam jagung di lahan tanpa olah tanah. Data kapasitas lapangan aktual (KLA) adalah 0,27 ha/jam, kapasitas lapangan teroritis (KLT) adalah $0,31 \mathrm{ha} / \mathrm{jam}$, dan efisiensi alat (EA) adalah 85,11\%. Jarak antar baris tanaman rata-rata adalah 20,87 $\mathrm{cm}$ dan lebar baris tanaman rata-rata adalah $35,06 \mathrm{~cm}$.

\section{Saran}

Nilai efisiensi alat tanam biji jagung sistem dorong baris ganda belum optimal. Untuk memperoleh nilai efisiensi yang tinggi, maka kondisi lahan perlu diolah terlebih dahulu agar alang-alang dan tumbuhan lain tidak mengganggu pada saat penanaman.

\section{DAFTAR REFERENSI}

Aisyah, Y., \& Herlina, N. (2018). Pengaruh Jarak Tanam Tanaman Jagung Manis (Zea mays L. var. saccharata) pada Tumpangsari Dengan Tiga Varietas Tanaman Kedelai (Glycine max (L.) Merrill). Jurnal Produksi Tanaman, 6(1), 66-75.

Andrade, F. H., Calvino, P., Cirilo, A., \& Barbier. (2002). Yield Responses to Narrow Rows Depend on Increased Radiation Interception. Agronomy Journal, 94, 975-980.

Ansar. (2011). Desain dan Uji Performansi Roda Sirip Lengkung Traktor Tangan untuk Pengolahan Tanah di 
Lahan Kering. Jurnal Agritech, 31(3), 201-206.

Ansar, Murad, Putra, G. M., \& Hartuti, H. (2020). Pemetaan Lahan Pertanian di Kabupaten Lombok Timur Menggunakan Sistem Informasi Geografis (SIG). Jurnal Teknik Pertanian Lampung, 9(2), 140-148.

Ansar, Sukmawaty, Sabani, R., \& Murad. (2020). Penerapan Alat Tanam Biji Jagung Sistem Dorong di Desa Gumantar Kabupaten Lombok Utara-NTB. Jurnal Abdi Mas TPB, 2(2), 32-37.

Ansar; Cahyawan; Safrani. (2012). Karakteristik Pengeringan Chips Mangga Menggunakan Kolektor Surya Kaca Ganda. Jurnal Teknologi dan Industri Pangan, 23(2), 153157.

Bolly, Y. Y. (2018). Pengaruh Jarak Tanam dan Jumlah Benih Perlubang Tanam Terhadap Pertumbuhan dan Hasil Tanaman Jagung Manis (Zea mays Saacaratha L.) Bonanza F1 di Desa Wairkoja, Kecamatan Kewapante, Kabupaten Sikka. Agrica, 11(2), 164-178.

Djoyowasito, G., Sutan, S. M., Hendrawan, Y., \& Hilmi, M. (2017). Uji Performansi Rancang Bangun Mesin Penanam Benih Jagung (Zea mays L.) Sistem Tugal. Jurnal Keteknikan Pertanian Tropis dan Biosistem, 5(1), 49-55.

Farida, N., Wiresyamsi, A., Budianto, V. F., Dahlan, M., \& Wangiyana, W. (2017). Pertumbuhan dan Hasil Tanaman Jagung Ketan pada Berbagai Jarak Tanam, Pola Barisan, dan Tumpangsari dengan Tanaman Legum di Lahan Sawah Entisol. Agroteksos: Agronomi Teknologi dan Sosial Ekonomi Pertanian, 25(1), $72-78$.

Hermawan, W. (2011). Perbaikan Desain Mesin Penanam dan Pemupuk Jagung Bertenaga Traktor Tangan. Jurnal Keteknikan Pertanian, 25(1), 9-18.

Idhansyah, Rantung, R. A., \& Ludong, D. P. (2019). Uji Teknis Alat Tanam Jagung (Zea mays L.) Tipe TP CSM 15 dengan Menggunakan Traktor Tangan sebagai Alat Penarik. Jurnal Cocos, 1(5), 1-7.

Iskandar, M., Syafriandi, \& Mustaqimah. (2017). Desain dan Pengujian Alat Tanam Benih Jagung. Jurnal Ilmiah Mahasiswa (JIM) Pertanian, 2(1), 314-319.

Jaya, I. K., Sudirman, \& Jayaputra. (2015). Karakteristik Pertumbuhan dan Daya Hasil Beberapa Jagung Varietas Hibrida yang Ditanam dengan Populasi Berbeda di Lahan Kering. Agroteksos, 25(1), 144-150.

Karima, S. K., Nawawi, M., \& Herlina, N. (2013). Pengaruh Saat Tanam Jagung dalam Tumpangsari Tanaman Jagung (Zea mays L.) dan Brokoli (Brassica oleracea L. var. botrytis). Jurnal Produksi Tanaman, 1(3), 87-92.

Khodijah, N. S., Kusmiadi, R., \& Sartika, S. (2014). Optimalisasi Produksi Kacang Tanah dan Jagung pada Pola Tanam Tumpangsari dengan Perlakuan Defoliasi Jagung. Enviagro, Jurnal Pertanian dan Lingkungan, 7(2), 1-6.

Marliah, A., Jumini , \& Jamilah. (2010). Pengaruh Jarak Tanam Antar Barisan pada Sistem Tumpangsari Beberapa Varietas Jagung Manis dengan Kacang Merah terhadap 
Pertumbuhan dan Hasil. Jurnal Agrista, 14(1), 30-37.

Nariratih, I., Damanik, B., Majid, M., \& Sitanggang, G. (2013). Ketersediaan Nitrogen pada Tiga Jenis Tanah Akibat Pemberian Tiga Bahan Organik dan Serapannya pada Tanaman Jagung. Jurnal Agroekoteknologi, 1(3), 479-488.

Neo, F. X., \& Ceunfin, S. (2018). Effect of Intercropping Models and Spacing Arrangement of Rice Bean (Vigna angularis L.) Local Cultivar on Growth and Yield Of Maize Plant (Zea mays L.). Savana Cendana, 3(1), 14-17.

Permanasari, I., \& Kastono, D. (2012). Pertumbuhan Tumpangsari Jagung dan Kedelai pada Perbedaan Waktu Tanam dan Pemangkasan Jagung. Jurnal Agroteknologi, 3(1), 13-20.

Pomalingo, M. (2020). Rancang Bangun dan Uji Kinerja Tugal Jagung untuk Lahan Miring. Jurnal Teknologi Pertanian Gorontalo (JTPG), 5(1), 1-8.

Sianipar, T. O., \& Fatoni, Z. (2019). Perancangan Alat Penanam Benih Jagung dan Penyiraman. Turbulen: Jurnal Teknik Mesin, 2(1), 25-32.

Silaban, E. T., Purba, E., \& Ginting, J. (2013). Pertumbuhan dan Produksi
Jagung Manis (Zea mays sacaratha strut L.) pada Berbagai Jarak Tanam dan Waktu Olah Tanah. Jurnal Agroekoteknologi Universitas Sumatera Utara, 1(3), 808-818.

Syafa'at, I., \& Subantoro, R. (2017). Perancangan Alat Penanam Benih Jagung Multi Fungsi bagi Masyarakat Singorojo Kendal. Jurnal Abdimas Unwahas, 2(2), 4044.

Syafruddin, Nurhayati, \& Ratnawati. (2012). Pengaruh Jenis Pupuk terhadap Pertumbuhan dan Hasil Beberapa Varietas Jagung Manis. Jurnal Floratek, 7, 107-114.

Wirawan, D. A., Haryono, G., \& Susilowati, Y. E. (2018). Pengaruh Jumlah Tanaman per Lubang dan Jarak Tanam terhadap Hasil. Jurnal Ilmu Pertanian Tropika dan Subtropika, 3(1), 5-8.

Wiresyamsi, A., Akraf, J., \& Ngawit, I. K. (2018). Pengaruh Jarak Tanam dan Pola Barisan Jagung terhadap Hasil Kedelai (Glycine max (L.) Merril) yang Ditanam-Sisip di antara Bekas Barisan Jagung. Crop Agro, Jurnal Ilmiah Budidaya, 5(2), 17-23.

Yulisma, Y. (2015). Pertumbuhan dan Hasil Beberapa Varietas Jagung pada Berbagai Jarak Tanam. Jurnal Penelitian Pertanian Tanaman Pangan, 30(3), 196-203. 